\title{
Genetic signatures of population bottlenecks, relatedness, and inbreeding highlight recent and novel conservation concerns in the Egyptian vulture
}

\author{
Guillermo Blanco $^{\text {Corresp., } 1}{ }^{,}$Francisco Morinha ${ }^{1}$ \\ ${ }^{1}$ Department of Evolutionary Ecology, National Museum of Natural Sciences (MNCN), Spanish National Research Council (CSIC), Madrid, Madrid, Spain \\ Corresponding Author: Guillermo Blanco \\ Email address: g.blanco@csic.es
}

The assessment of temporal variation in genetic features can be particularly informative on the factors behind demography and viability of wildlife populations and species. We used molecular methods to evaluate neutral genetic variation, relatedness, bottlenecks, and inbreeding in a declining population of Egyptian vulture (Neophron percnopterus) in central Spain. The results show that the genetic diversity remained relatively stable over a period of twelve years despite the decline in census and effective population sizes in the last decades. A relatively high proportion of nestlings from different and distant territories showed high relatedness in each study year. We also found support for an increasing impact of severe recent (contemporary) rather than distant (historical) past demographic bottlenecks, and the first evidence of inbred mating between full siblings coinciding with lethal malformations in offspring. The inbred nestling with feather malformations was positive to beak and feather disease virus recorded for the first time in this species. These results alert on recent and novel threats potentially affecting health and reducing the adaptive potential of individuals in this threatened species. 


\section{Genetic signatures of population bottlenecks,}

2 relatedness, and inbreeding highlight recent and

3 novel conservation concerns in the Egyptian vulture

4

5

7

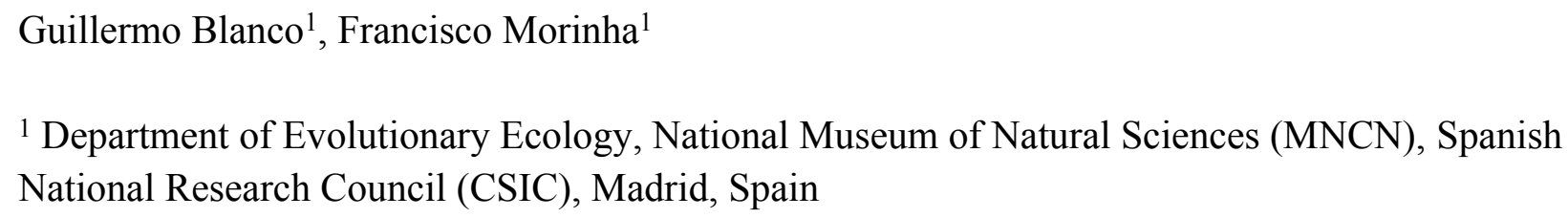

\section{Abstract}

The assessment of temporal variation in genetic features can be particularly informative on the factors behind demography and viability of wildlife populations and species. We used molecular methods to evaluate neutral genetic variation, relatedness, bottlenecks, and inbreeding in a declining population of Egyptian vulture (Neophron percnopterus) in central Spain. The results show that the genetic diversity remained relatively stable over a period of twelve years despite the decline in census and effective population sizes in the last decades. A relatively high proportion of nestlings from different and distant territories showed high relatedness in each study year. We also found support for an increasing impact of severe recent (contemporary) rather than distant (historical) past demographic bottlenecks, and the first evidence of inbred mating between full siblings coinciding with lethal malformations in offspring. The inbred nestling with feather malformations was positive to beak and feather disease virus recorded for the first time in this species. These results alert on recent and novel threats potentially affecting health and reducing the adaptive potential of individuals in this threatened species. 
38

39

40

41

42

43

44

45

46

47

48

49

50

51

52

53

54

55

56

57

58

59

60

61

62

63

64

65

66

67

68

69

70

71

72

73

74

75

76

77

\section{Introduction}

The assessment of genetic diversity is crucial to understanding trends of wildlife populations and to implementing adequate strategies for conservation of endangered species (Willi, Van Buskirk \& Hoffmann, 2006; Frankham, 2010). The evaluation of temporal variation in genetic diversity, bottlenecks, and relatedness can be particularly informative on the factors behind demography and viability of wild populations (Frankham, Ballou \& Briscoe, 2002; Wootton \& Pfister, 2013). This variation is often correlated with census size and population fragmentation depending on natural and anthropogenic threats (Frankham, Ballou \& Briscoe, 2002; O 'Grady et al., 2004). Both genetic and environmental factors also interact to determine individual health and fitness further contributing to demography and population dynamics (Keller et al., 2002; Reed, Briscoe \& Frankham, 2002; Allentoft \& O'Brien, 2010). During the last decades, anthropogenic activities have exerted increasing impacts on biodiversity worldwide. Among the main detrimental factors, disease is an increasing threat with anthropogenic change (Martin et al., 2010; Becker, Streicker \& Altizer, 2015; Cunningham, Daszak \& Wood, 2017) combined with low diversity impacting ability to fight parasites and pathogens (Spielman et al., 2004; Gupta, Robin \& Dharmarajan, 2020).

Relatedness levels among individuals can be used as an indicator of genetic diversity in wildlife populations and species. The mating between close relatives can cause the loss of genetic variation due to random genetic drift, increasing the expression of recessive deleterious alleles, the loss of heterozygosity, and the extinction of functionally important alleles in the population (Keller \& Waller 2002; Charlesworth \& Willis 2009). Inbreeding in bird populations may result in several negative biological effects such as hatching failure, low offspring survival, and unviability due to physiological alterations and morphological malformations (Keller \& Waller 2002; Gupta, Robin \& Dharmarajan, 2020). Therefore, inbreeding can influence the persistence of small and isolated populations by accelerating the extinction process in critically endangered species (Brook et al., 2002; Frankham, Ballou \& Briscoe, 2002; O'Grady et al., 2006). This may arise especially if population decline is experienced quickly in recent history, rather than over long periods across the demographic history of species, thus respectively precluding and allowing the purging of deleterious alleles (Crnokrak \& Barrett 2002; Fox, Scheibly \& Reed, 2008; Leberg \& Firmin 2008). These processes can be linked to recent and historic genetic bottlenecks differentially contributing to a progressive simultaneous reduction of genetic diversity and effective population size, and to the effects of inbreeding (Keller \& Waller 2002; Bouzat, 2010).

Multiple life-history traits and environmental factors can modulate the gain and loss of neutral genetic variation of populations and species (Lande, Enger \& Scether, 2003; Holderegger $\&$ Wagner 2008). In long-lived species, this balance may be especially influenced by high maturity time, slow metabolism, and particular demographic, spatial, and social structure of populations, acting as buffer or promoting factors against population fluctuations and trends (Roff, 2002; Scether et al., 2013). Therefore, any environmental and demographic alteration of these traits can increase stochasticity exerting pervasive effects on population size and genetic 
variation (Lande, Enger \& Scether, 2003; Palstra \& Ruzzante 2008; Jeppsson \& Forslund 2012). Among large long-lived birds, vultures provide a case study of certain extreme life history traits (van Overveld et al., 2020), so they may be excellent models to study the impact of environmental and demographic stochasticity, and to test predictions on contemporary and historical variation in neutral genetic diversity, population trends, and extinction risk. Despite vultures being one of the most threatened groups of birds, the information on genetic diversity of populations and species is still limited (Godoy et al., 2004; Poulakakis et al., 2008; MartínezCruz \& Camarena, 2018; Çakmak et al., 2019; Kleinhans \& Willows-Munro, 2019; Davidović et al. 2020). As a consequence, there is a paucity of information on whether the interaction between life history traits, environmental features, and population characteristics can shape a genetic influence on the persistence and conservation of their populations. In particular, the spatial distribution of population nuclei interconnected by dispersing individuals contributing to gene flow is an important factor shaping patterns of genetic diversity throughout a species' range (Holderegger \& Wagner, 2008; Lowe \& Allendorf, 2010), often associated to social behaviour and individual recognition of close relatives (Pusey \& Wolf, 1996; Hatchwell, 2010). These factors can arise to minimize mean kinship within the population and prevent inbreeding, but no information is available on these mechanisms in vultures (van Overveld et al., 2020). In addition, there is scarce knowledge on pathogens affecting vultures (Plaza, Blanco \& Lambertucci, 2020) and no information on the interactions between genetic erosion, inbreeding, and disease. This knowledge is paramount to implement in-situ conservation management measures, and ex-situ actions such as captive breeding and reintroduction.

In this study, we used molecular methods to evaluate neutral genetic variation and relatedness in a declining population of Egyptian vulture (Neophron percnopterus) in central Spain. The main causes of the generalized decline of the Egyptian vulture includes illegal persecution through poisoning, habitat degradation, and reduction of food resources (BirdLife International, 2019). In addition, as consequence of the dependence on carrion of industriallyreared swine exploited at supplementary feeding stations across the study area (Blanco, 2014), this population has been recorded as highly exposed to pig-adapted Salmonella serotypes and to livestock antibiotics and resistant bacteria to these drugs (Blanco, 2018; Blanco, Junza \& Barrón, 2017; Blanco et al., 2020). Antibiotics ingested from livestock carcasses have been suggested behind immunosuppression, microbiota dysbiosis, and proliferation of opportunistic pathogens like yeast, filamentous fungi, and bacteria causing oral disease that can cause nestling mortality (Blanco, Junza \& Barrón, 2017; Pitarch, Gil \& Blanco 2017, 2020; Blanco et al. 2019). Previous studies have not highlighted the loss of genetic diversity as a main threat for the Egyptian vulture (BirdLife International, 2019) except in insular populations (Agudo et al., $2011 b$; 2012).

As part of the long-term population monitoring, we recorded the identity of banded breeders to determine the nest of birth, natal dispersal, and reproductive success. To assess whether genetic diversity, relatedness, and inbreeding have changed in recent times, we compared these traits in two breeding seasons from the last two decades (2006 and 2018). In 
118 addition, we evaluated patterns and temporal variation in genetic signature of recent and historic 119 demographic processes through bottleneck analysis. To further investigate inbreeding and its

120

121

122

123

124

125

126

127

128

129

130

131

132

133

134

135

136

137

138

139

140

141

142

143

144

145

146

147

148

149

150

151

152

153

154

155

156

157

potential negative consequences, we examined the genetic relationships among nestlings fledged from a particular territory during a period of 15 years. Two of these nestlings subsequently mated, which allowed us to retrospectively investigate genetic relatedness and pedigree relationships between them and its influence in breeding performance and offspring health. This aimed to determine the extent of inbreeding as a relevant factor to be considered in the conservation management of this declining species.

\section{Materials \& Methods}

\section{Study species and study area}

The Egyptian vulture is a small $(\sim 2 \mathrm{~kg})$ obligate scavenger living in a variety of open, arid, montane, and rugged landscapes in Southern Europe, Africa, and Asia (Cramp \& Simmons, 1980; Del Hoyo, Elliott \& Sargatal, 1994). Breeding adults nest on cliffs, defend territories against conspecifics, and behave as solitary or social foragers depending on the abundance, predictability, and concentration of food resources. Carcasses of wild animals (e.g. ungulates, lagomorphs, birds, and reptiles) and livestock represent the main food sources during the breeding season (Donázar, 1993; Blanco, Junza \& Barrón, 2017; Blanco et al., 2019). Egyptian vultures are monogamous, highly philopatric, and territorial during the breeding season (Donázar, 1993; Sanz-Aguilar et al. 2017). This species shows a slow pace of life, with long generation time (14 years according to BirdLife International, 2019), average age of first breeding in the $7^{\text {th }}$ year of age, low fecundity and reproductive rate (clutch size: 2 eggs; $0-2$ fledglings per breeding attempt), and long lifespan (maximum age recorded in the wild: 24 years) (Sanz-Aguilar et al., 2017). This species is categorized globally as Endangered due to severe long-term declines through much of the distribution range (BirdLife International, 2019). The bulk of the European population is concentrated in Spain (about 1500 pairs), where the breeding population has showed a strong decline in the last decades (BirdLife International, 2019).

The study was conducted in the province of Segovia (Castilla y Léon, Central Spain). This area holds a small and declining population of Egyptian vultures mostly nesting in cliffs located in two major systems of large gorges in two protected areas (Natural Parks of Hoces del Río Duratón and Hoces del Río Riaza) and their surroundings, while isolated pairs nest in small and scattered cliffs. The breeding population has suffered a sharp decline in the study area since the 1990s (from 48 pairs in 1993 to 27 pairs in 2019; del Moral, 2009; Sanz-Aguilar et al., 2017). This population has been genetically characterized as forming part of the central-northern cluster from the distribution range in Iberia, including breeding sub-nuclei in Navarra and Aragón, north-eastern Spain (Agudo et al., 2011a). The Egyptian vulture pairs nesting in the area between

Peer) reviewing PDF | (2020:12:56011:1:1:NEW 9 Feb 2021) 
158 Segovia province (the study area) and the northern distribution range in Iberia are also expected

159

160

161

162

163

164

165

166

167

168

169

170

171

172

173

174

175

176

177

178

179

180

181

182

183

184

185

186

187

188

189

190

191

192

193

194

195

196

197

to belong to the same genetic cluster (Agudo et al., 2011a), as indicated by natal dispersal involving emigrants and immigrants recruited as breeders throughout this area (Serrano et al., in review). Overall, for 19 Egyptian vultures recruited in or from the study area between 5 and 10 years after being marked as nestlings since 2003, we recorded a median dispersal distance of $41.2 \mathrm{~km}$ (range: $5.5-201$ ). Most of the individuals recruited as breeders in the study area correspond to those also born in the study area (13 of 16). The remaining individuals were recruited in neighbouring provinces (Burgos and Soria respectively), while another individual was recruited in a more distant province (Zaragoza, Ebro Valley, north-eastern Spain). In addition, only two immigrant individuals born in the province of Zaragoza were recruited in the study area, while another individual born in Zaragoza was recruited in a neighbouring province (Guadalajara) to the study area. The study was carried out in accordance with the permission of the regional government of Castilla y Léon, Dirección General del Medio Natural, Servicio de Espacios Naturales.

\section{Fieldwork and sampling procedures}

An intensive monitoring program, including searching for territories, ringing nestlings, and identifying banded breeding individuals at territories was conducted at the Segovia province and its surroundings during the last four decades (Martinez \& Blanco 2002; Sanz-Aguilar et al., 2017). The nests were accessed by climbing when nestlings were feathered (at ages of about 50 days) but without risk of leaving the nests. The clutch size in this species is of two eggs, but in a proportion of nests only one nestling survives, mostly the first-hatched nestling (Donázar et al., 2020). Therefore, sampled nestlings can correspond to the single nestling in the nest (brood size $=1$ ) or two siblings in the same nest (brood size $=2)$. Nestlings $(n=180)$ were measured, weighed, and banded with metal and plastic rings with alphanumeric codes allowing individual identification at long distance with terrestrial telescopes. A sample of blood as source of DNA was taken from the brachial wing vein and preserved in absolute ethanol.

To evaluate temporal trends in genetic relatedness, bottlenecks, and inbreeding in the population, we selected nestlings sampled in 2006 ( $n=19$ from 15 territories) and 2018 ( $n=14$ from 10 territories). The sampled nestlings correspond to about $40-50 \%$ of the active territories each year in the population, as a variable proportion of breeding pairs failed in the reproduction each year (Martinez \& Blanco 2002; Sanz-Aguilar et al., 2017). Each territory can include several nesting sites, but only a particular nesting site is used each year in each territory. Therefore, we sampled a relatively well-represented proportion of the territories available for nestling sampling each study year. Overall, our study includes the sampling of 42 Egyptian vulture individuals (see Appendix S1).

In the breeding season of 2017, we located a novel breeding pair composed of two individuals born in the same nest but in different years. Because breeders can use the same nest and territory year to year (Sanz-Aguilar et al., 2017), we assessed whether these individuals were

Peer] reviewing PDF | (2020:12:56011:1:1:NEW 9 Feb 2021) 
198

199

200

201

202

203

204

205

206

207

208

209

210

211

212

213

214

215

216

217

218

219

220

221

222

223

224

225

226

227

228

229

230

231

232

233

234

235

236

genetically related or if they simply born in the same territory used by different breeders in different years. To this aim, we evaluated the relatedness among the nestlings $(n=10)$ born in $2004(n=1), 2005(n=1), 2006(n=1), 2007(n=2), 2010(n=2), 2018(n=2)$ and $2020(n=1)$ in the two nesting sites (distant $<200 \mathrm{~m}$ ) included in this single territory (a single nesting site used each year). This allowed us to evaluate the validity of the relatedness estimates in reflecting full-sib relationships. To determine whether the same breeders used the same territory across the years, we collected feathers of the breeders attending this particular territory during the nest access to band the nestlings in 2018. We wanted to determine whether these breeders were the parents of the nestlings raised in the same territory the previous years, and then to establish long-term nest re-use and changes in the composition of the pair mate.

\section{DNA extraction, molecular sexing and microsatellite genotyping}

The DNA was isolated by using the Quick-DNA Miniprep Plus Kit (Zymo Research) according to manufacturer's protocols. Molecular sexing was performed using specific primers for partial amplification of the CHD1 gene (Fridolfsson \& Ellegren 1999).

Seventeen microsatellite markers previously characterized for Egyptian vulture were analysed: BV9, BV13, BV14, BV20, NP39, NP51, NP93, NP140, NP141, NP155, NP163, NP166, NP229, NP249, NP257, NP259, and NP296 (Kretzmann et al., 2003; Agudo et al., 2008). Microsatellite forward primers were labelled with 6-FAM, NED, PET, and VIC fluorescent dyes to determine the genotypes using capillary electrophoresis. PCR amplifications were performed in a total volume of $10 \mu \mathrm{l}$ containing $5 \mu \mathrm{l}$ of $2 \mathrm{x}$ MyTaq HS Mix (Bioline), $2 \mu \mathrm{M}$ of each primer, and $5 \mathrm{ng}$ DNA. PCR thermal conditions were as follows: initial denaturation at $95{ }^{\circ} \mathrm{C}$ for $5 \mathrm{~min}$, followed by 40 cycles of $95{ }^{\circ} \mathrm{C}$ for $30 \mathrm{~s}, 58{ }^{\circ} \mathrm{C}$ for $1 \mathrm{~min}, 72{ }^{\circ} \mathrm{C}$ for $30 \mathrm{~s}$, and a final extension at $60^{\circ} \mathrm{C}$ for $10 \mathrm{~min}$. Amplified fragments were electrophoresed on an ABI PRISM 3130xl Genetic Analyzer (Applied Biosystems) using the GeneScan 500 ROX size standard. Allele sizes were determined using Peak Scanner v.3.0 (Thermo Fisher Cloud) and are presented as supplementary data (Appendix S1).

\section{Evaluation of microsatellite loci quality and genetic diversity}

The screening of genotyping errors, large allele dropout, null alleles, and stuttering were performed with MICRO-CHECKER v.2.2.3 (Van Oosterhout et al., 2004) using Bonferroni (Dunn-Sidak) adjusted confidence intervals (95\%) obtained after 10,000 Monte Carlo simulations. The significance of linkage disequilibrium (LD) and deviations from HardyWeinberg equilibrium were assessed using GENEPOP v.4.4.2 (Rousset, 2008) applying the Markov chain method (10,000 dememorisation steps, 1000 batches and 5000 iterations/batch), and a sequential Bonferroni correction. The number of alleles per locus $\left(N_{A}\right)$, observed and expected heterozygosities $\left(H_{O}\right.$ and $\left.H_{E}\right)$ were calculated with GENALEX v.6.5 (Peakall \&

Peer] reviewing PDF | (2020:12:56011:1:1:NEW 9 Feb 2021) 
237 Smouse, 2012). Allelic richness $\left(A_{R}\right)$ values were obtained using FSTAT v.2.9.3.2 (Goudet, 238 1995).

239

240

241

242

243

\section{Analysis of genetic differentiation}

244

245

246

247

248

249

250

251

252

253

254

255

256

257

258

259

260

261

262

263

264

265

266

267

268

269

270

271

272

273

274

275

276

The possible genetic differentiation between offspring from 2006 and 2018 was assessed using the $F_{S T}$ estimator of Weir \& Cockerham (1984), as implemented in GENALEX v.6.5. Allele frequency differentiation between samples of 2006 and 2018 was tested using Fisher's exact test in GENEPOP v.4.4.2. We carried out a multi-locus spatial autocorrelation analysis (Smouse \& Peakall, 1999) for both sampling years pooled and independently by using GENALEX. The spatial autocorrelation coefficient of genetic distance $(r)$ was estimated for a maximum of 9 distance classes (a total distance of $90 \mathrm{~km}$ ). Significance tests for each distance class were performed using 9,999 random permutations and 9,999 bootstrap replicates. In addition, we performed a Bayesian clustering analysis using the program STRUCTURE v.2.3.4 (Pritchard, Stephens \& Donnelly, 2000). The analysis consisted of 10 independent runs for $\mathrm{K}$ values ranging from 1 to 3, each with 1,000,000 MCMC iterations after a burn-in of 100,000 interactions, under a model of admixture and correlated allele frequencies. The outputs were processed in the CLUMPAK server (Kopelman et al., 2015).

\section{Genetic relatedness and inbreeding measures}

Various studies have been reported that genome-wide single nucleotide polymorphisms (SNPs) may outperform microsatellite markers in kingship assignment and relatedness estimations (e.g. Hauser et al. 2011, Weinman, Solomon \& Rubenstein, 2015; Thrasher et al., 2018). However, the microsatellites could be also a reliable choice if (i) there is a microsatellite panel available for the species under study, (ii) the markers have suitable polymorphic levels, (iii) they have a good resolution power and (iv) DNA samples have low-quality to generate reliable genome wide SNPs (Flanagan \& Jones, 2019). We selected a well-known microsatellite panel previously developed and applied in population genetic studies of Egyptian vultures for our relatedness approaches, taking into account all these factors, our target species and the biological samples. Relatedness $(r)$ among individuals was calculated using different estimators to evaluate the robustness and reliability of our inferences, since the performance of the different relatedness algorithms are dependent of the dataset used (Anderson \& Weir, 2007; Wang, 2014). The COANCESTRY application (Wang, 2011) was used to test the performance of five relatedness estimators reported by Wang (2002), Lynch \& Li (Lynch, 1988; Li, Weeks \& Chakravarti, 1993), Lynch \& Ritland (1999), Ritland (1996) and Queller \& Goodnight (1989). The pairwise relatedness values (dyads) were calculated and the best estimators were evaluated using the reference values obtained for the know full-sib relationships (full-sibs 1V5, 1V9 and G15749; full-sibs 290, 291, 32U, 32T, 9MA and 9LX; full-sibs 9MC and MF; see Appendix S1). The mean pairwise relatedness estimated from these individuals were compared with the theoretically

Peer) reviewing PDF | (2020:12:56011:1:1:NEW 9 Feb 2021) 
277 expected value for full-siblings (0.5). Relatedness were also estimated for the group of all 278 Egyptian vultures included in the study (a value less than 0.5 is expected). GENALEX v.6.5 279 (Smouse \& Peakall, 2012) was applied to generate the tridiagonal matrix of pairwise estimates of 280 relatedness using the Queller and Goodnight's estimator (QG-r), which minimizes a downward 281 bias for small sample sizes (Queller \& Goodnight, 1989). The ML-RELATE software 282 (Kalinowski, Wagner \& Taper, 2006) was used to estimate the genetic relationships between all 283 individual vultures. This program calculates the maximum likelihood estimates of relatedness 284 (ML-r) and relationship categories between pairs of individuals from genotypic data. The 285 likelihood values of the relationships available from the software (U, Unrelated; HS, Half sib; 286 FS, Full sib; PO, Parent-Offspring) were calculated to determine the relationship with highest 287 likelihood for each pair of individuals. When individuals born in the same year were categorized 288 as PO, kinship was assumed to be FS. The inbreeding coefficients $\left(F_{I S}\right)$ were estimated using

289

290

291

292

293

294

295

296

297

298

299

300

301

302

303

304

305

306

307

308

309

310

311

312

313

314

315

316 GENEPOP v.4.4.2 (Rousset, 2008) to assess the level of inbreeding in the groups of individuals analysed. The program CERNICALÍN v.1 (Aparicio, Ortego \& Cordero, 2006) was used to calculate the homozygosity by loci (HL), estimating the indices of inbreeding considering the proportion of loci within the genotypes of an individual that are homozygous. Statistical differences between years in the parameters of genetic diversity, relatedness, and inbreeding were assessed by Mann-Whitney U-test.

The spatial pattern of relatedness was tested by two-tailed Mantel test with 9,999 permutations considering the geographic distances (in km) between nests (Appendix S2) and the QG- $r$ and ML- $r$ values of each nestling from 2006 and 2018 (a single nestling per nest selected at random was considered in the case of broods with two siblings to avoid pseudoreplication).

\section{Demographic events and effective population sizes}

The detection of potential bottleneck events that lead to severe population size reductions in the recent (contemporary) past over the last decades was performed using the program

BOTTLENECK version 1.2.02 (Piry, Luikart \& Cornuet, 1999). The stepwise mutation model (SMM), infinite allele model (IAM), and two-phase mutation (TPM) model and mode-shift test were used. This analysis was complemented with the M-ratio model implemented in the software M_P_VAL (Garza \& Williamson 2001), which allows the detection of bottlenecks that occurred in the recent and distant (historical) past over centuries or millennia (Piry, Luikart \& Cornuet, 1999; Williamson-Natesan, 2005). All parameters used in the analysis were previously described (see Blanco et al. 2021).

The contemporary effective population size $\left(N_{e}\right)$ was estimated using the program LDNE v.1.31 (Waples \& Do 2008). The random mating model was used. Alleles with frequencies lower than 0.02 were excluded and the confidence intervals were obtained using jack-knife statistics.

\section{Screening of infectious agents}


317 The inbred offspring (nestling with feather malformations, ref: 9MC from 2018; and nestling 318 apparently healthy, ref: $9 \mathrm{MF}$ from 2020) were analysed for the presence of three potential 319 infectious agents that can cause plumage alterations (beak and feather disease virus, BFDV; 320 avian polyomavirus, APV; and Salmonella). Specific molecular markers previously reported

321

322

323

324

325

326

327

328

329

330

331

332

333

334

335

336

337

338

339

340

341

342

343

344

345

346

347

348

349

350

351

352

353

354

355

356 were used in the PCR screening of BFDV (Amery-Gale et al., 2017) and APV (Johne \& Müller, 1998). PCR was performed in a reaction mixture of $10 \mu \mathrm{l}$ containing $5 \mu \mathrm{l}$ of 2x MyTaq HS Mix (Bioline), $2.5 \mu \mathrm{M}$ of each primer and $\sim 20 \mathrm{ng}$ of template DNA. The amplification protocol was composed of the following steps: $95^{\circ} \mathrm{C}$ for 5 min followed by 40 cycles of $95^{\circ} \mathrm{C}$ for $30 \mathrm{~s}$, annealing at $58^{\circ} \mathrm{C}$ for $1 \mathrm{~min}, 72^{\circ} \mathrm{C}$ for $30 \mathrm{~s}$, and a final extension at $60^{\circ} \mathrm{C}$ for $10 \mathrm{~min}$. To determine the presence of Salmonella, nestlings were sampled for cloacal mucosa using sterile microbiological swabs with Amies transport medium. The samples were analysed by conventional microbiological culture (ISO 6579:2002/Amd. 1:2007) and by using the real-time PCR IQ-CHECK ${ }^{\mathrm{TM}}$ Salmonella II kit (Bio-Rad) and Easy I protocol, according to the manufacturer's instructions (see details of both methods in Blanco \& Díaz de Tuesta, 2018, 2020).

\section{Ethics statement}

Our study followed ethical guidelines proposed for the Spanish Royal Decree 1205/2005 on the protection of animals used in experiments and scientific research. The study was carried out in accordance with permits from the Spanish Bird Ringing Centre (Permit Number: 530115), and the regional government of Castilla y Léon (Expte: EP/CyL/298/2016).

\section{Results}

\section{Genetic data quality, genetic diversity and differentiation}

The probability of null alleles was negligible for all loci except for NP140 (dataset of all individuals and offspring 2018). Therefore, the subsequent analyses were carried out with and without this locus. The results were similar when NP140 was included and excluded from the data set. Therefore, we present the results including this locus. Only the loci NP140 (offspring 2018) showed a significant deviation from Hardy-Weinberg equilibrium (HWE) after Bonferroni correction. When all individuals were analysed in the same dataset no significant deviation from HWE was observed (Table S1). Exact tests for genotypic LD confirmed the absence of physical linkage at most loci. Only two significant linkages were found; however, these significances were lost when all siblings were removed from the dataset. In this context, all microsatellite loci were included in the multilocus analysis.

All microsatellite loci were polymorphic, with a total of 75 different alleles amplified. The number of alleles per locus ranged from two (BV14, BV20 and NP257) to eight (NP39), 
357

358

359

360

361

362

363

364

365

366

367

368

369

370

371

372

373

374

375

376

377

378

379

380

381

382

383

384

385

386

387

388

389

390

391

392

393

394

395

396

with an average of four alleles (Table S1). In the offspring of 2018, only one allele for the locus NP51was detected. Mean values of $A_{R}, H_{O}$, and $H_{E}$ did not differ between nestlings from 2006 and 2018 (Table 1).

Genetic differentiation was not significant between offspring from 2006 and 2018 ( $F_{S T}=$ $0.02, p=0.38$ ). No significant differences were detected when Fisher's exact tests of genetic differentiation were calculated from allele frequency data (Table S2). We found no evidence of genetic spatial autocorrelation when all individuals were analysed together and when the offspring of 2006 and 2018 were analysed as independent groups (Figure S1). The results of Bayesian clustering analysis also show no evidence of genetic structure and differentiation between years (Figure S2).

\section{Relatedness}

The evaluation of the five genetic relatedness estimators showed a good performance for most of the estimators (Table S3; Appendix S3). The estimators that allowed a better identification of the true full-sibs using the relatedness values were Wang $(0.59 \pm 0.13)$, Lynch \& $\mathrm{Li}(0.60 \pm 0.12)$ and Queller \& Goodnight $(0.60 \pm 0.12)$ (Table S3). The mean relatedness values when all individuals were analysed were also very similar for all estimators, ranging from $-0.02 \pm 0.24$ (Queller \& Goodnight) to $-0.01 \pm 0.26$ (Wang and Lynch \& Li) (Table S3). In addition, most of the pairwise values obtained for the five estimators were highly correlated (average correlation value of $0.87 \pm 0.07)$ (see Table S4 for pairwise correlation values). Therefore, for simplification purposes, we showed only the relatedness values for Queller \& Goodnight estimates (QG-r) in the following analysis.

Measures of QG- $r$ (Appendix S4) and ML-r (Appendix S5) were highly correlated (Mantel test: $r=0.835 ; p<0.0001$ ). The strategy used for categorizing the genetic relationships allowed the accurate assignment of all direct relationships in individuals with known pedigree, and only two deviations in the kinship assignation were observed for inferred relationships. Overall, we correctly assigned $93 \%$ ( 26 of the 28 pair-wise relationships) obtained for the group of individuals with known pedigree. Therefore, it is expected that relationship categories estimated for individuals with unknown pedigree reflect the actual relatedness with accuracy. For nestlings from 2006, 33 half-sib (19.8\%) and three full-sib (1.8\%) relationships were estimated, excluding the four full-sibs from broods of two nestlings reared in the same nest and year (Appendix S6). For nestlings from 2018, 13 half-sibs (14.9\%) and four full-sibs (4.6\%) relationships were estimated, excluding the four full-sibs from the same nest (Figure 1A; Appendix S6). The geographic location of the territories sampled in 2018 is shown in Figure 1B. The proportion of nestlings in each kinship category did not differ between years (Fisher exact test, $p=0.19$ ), being about $20 \%$ those estimated being closely related individuals (half and full-sibs) when pooled years; for this analysis, we considered a single nestling selected at random from broods of two nestlings to avoid pseudoreplication. Mean values of relatedness and inbreeding were similar between nestlings from 2006 and 2018 (Table 1). The HL values for offspring of 2006 ranged 
397

398

399

400

401

402

403

404

405

406

407

408

409

410

411

412

413

414

415

416

417

418

419

420

421

422

423

424

425

426

427

428

429

430

431

432

433

434

435

436

from 0.19 to 0.52 (mean $=0.33 \pm 0.09)$, while these values were slightly higher (mean $=$ $0.39 \pm 0.10$ ) in offspring from 2018 (range $=0.26-0.59$ ), indicating that on average $35-50 \%$ of an individuals' loci are homozygous (Table 1; Table S5).

All territories showed at least one closely related individual (full or half sib) among the nestlings sampled in $2006(100 \%, n=15$ territories), and most territories in $2018(90 \%, n=10)$. The number of territories with closely related nestlings ranged from one to seven in 2006, and from zero to four in 2018 (Figure 2; see also Figure 1A, B for the specific and geographical representations of these relationships in 2018). Relatedness between nestlings from different nests (Figure 1A for 2018) showed no apparent spatial pattern (Figure 1B), as inter-nest distance was not significantly correlated with QG- $r$ and ML- $r$ values of each nestling from 2006 ( $r=$ $0.06, p=0.62, n=105 ; r=-0.08, p=0.43, n=105$, respectively) and $2018(r=0.13, p=0.35, n$ $=45 ; r=0.08, p=0.57, n=45$, respectively).

\section{Demographic history and effective population sizes}

The analysis with BOTTLENECK suggests population contractions in the recent past by analysing the samples from 2006 and 2018 populations (Table 2). Evidence of recent bottlenecks was found through SMM and the mode-shift test in 2006 and through all models in 2018 (Table 2). The M-ratio test does not support the occurrence of bottleneck events in a more distant (historical) past (values of $\mathrm{M}>\mathrm{Mc}$ ) (Table S6). Similar results were attained when nestlings from different territories and years were pooled to increase sample size (Table 2; Table S6).

Estimates of effective population size $\left(N_{e}\right)$ for each sampled year were 100 (CI=24-inf) for 2006 and $48\left(\mathrm{CI}=13\right.$-inf) for 2018. The value of $N_{e}$ considering all sampled individuals $(2006+2018)$ was $53(\mathrm{CI}=26-314)$.

\section{Long-term genetic relationships and inbreeding effects in a familiar lineage}

The retrospective analysis of relatedness in the sampled familiar linage showed a replacement of the mated pair present in 2004-2006 by another pair in 2007-2018 in this particular territory. This was confirmed by several facts: (i) nestlings from 2004-2006 were full sibs, and therefore shared the same progenitors; (ii) nestlings from 2007, 2010, and 2018 were also full sibs (Figure 3) but unrelated to nestlings from 2004-2006 except for a single half-sib relationships, and therefore were offspring of a different breeding pair; (iii) nestlings from 2007-2018 showed parentoffspring relationships with their putative parents sampled for feathers in 2018 (Figure 3); (iv) nestlings from 2004-2006 were unrelated with the female breeder but showed half-sib relationships with the male breeder in 2018 (Appendix S6).

Mean relatedness values for the familiar group from 2007 to 2018 was high (QG- $r=$ $0.62 \pm 0.11$; ML- $r=0.53 \pm 0.12$ ), as is expected for dyads of closely related individuals. Two of these full siblings mated between them (QG- $r=0.59$; ML- $r=0.43$ ) in 2017: a female (ref. 291) born in 2007 and a male (ref. 32U) born in 2010 (Figure 3), and nested in a territory distant 59 
$437 \mathrm{~km}$ from their natal nest (Figure 1B). We found two half-sib relationships in this familiar lineage 438 (Figure 3): (i) between the male breeder (ref. M) and his granddaughter (ref. 9MC) from the 439 inbred pair (refs. 291-32U); (ii) between a nestling from 2017 (ref. 290) and the son (ref. 9MF) 440 of the inbred pair (refs. 291-32U). A single half-sib relationship was recorded by molecular 441 methods between two actually full-sibs from different cohorts in this territory, which suggest 442 slight deviations in the kinship assignation due to allelic frequency. Relatedness of all offspring 443 with their actual parents and grandfathers were confirmed by pedigree and molecular methods. 444 Note, however, that the ML-RELATE software may not differentiate true full-sibs and parent445 offspring relationships in familiar cases with many closely related individuals, but these 446 relationships were ascertained in individuals with known pedigree in this familiar lineage. The inbred pair failed to reproduce in 2017. In 2018, the same pair reared a female offspring (ref. 9MC) that was confirmed to be daughter of their putative parents by microsatellite allelic patterns (Appendix S6) and relatedness values (QG- $r=0.72 \pm 0.18$; ML- $r=0.64 \pm 0.19$ ). This nestling showed alterations in feather structure and appearance across all the plumage (Figure 4A). These acute malformations mainly consisted in greasy plumage, constricted calamus in all flight feathers with barbs appearing only in the distal part, and pinched appearance in a proportion of feathers (Figure 4B). As a consequence of these severe and generalized malformations, this individual was unable to fly, and was retired by competent authorities and

455

456

457

458

459

460

461

462

463

464

465

466

467

468

469

470

471

472

473

474

475

476 admitted in a wildlife recovery centre. In 2019, the same inbred pair failed in the reproduction apparently due to nestling predation. In 2020, the same pair produced an apparently healthy offspring (ref. 9MF) that was confirmed as son of their putative parents by microsatellite allelic patterns (Appendix S6) and relatedness values (QG- $r=072 \pm 0.07$; ML- $r=0.60 \pm 0.07$ ). This nestling was confirmed as full-sib of the nestling with feather malformations in 2018 (QG- $r=$ 0.73 ; ML- $r=0.64$ ), and as full-sibs with all other nestlings from this family lineage in 20072018 (Figure 3). Values of HL were high for both inbreed individuals (Ref. 9MC =0.48; Ref. $9 \mathrm{MF}=0.54)$ as expected for offspring from parental full-sibs (Table S5).

The screenings of infectious agents performed in these inbreed offspring showed a BFDV positive result in the nestling with malformations (Ref. 9MC) and negative results for APV and Salmonella. All results were negative in the nestling apparently healthy (Ref. 9MF).

\section{Discussion}

\section{Genetic diversity, relatedness and inbreeding}

A growing body of evidence has related reduction in genetic diversity with declining population size of wild species (Frankham, 1996; Willoughby et al., 2015). Our data show that the genetic diversity in a small open population of Egyptian vulture remained relatively stable despite of its decline in census and effective population size in the last decades. A relatively high proportion of nestlings from different and distant territories showed high relatedness in each study year. In 
477 addition, we found an increasing impact of recent demographic bottlenecks and the first evidence 478 of mating between full siblings coinciding with lethal malformations in offspring.

479 We found similar levels of genetic variability and non-significant differences between 480 two breeding seasons twelve years apart. This lack of inter-year differences is not surprising 481 considering that the time period between both study years (12 years) is shorter that the 482 generation time in the Egyptian vulture (14 years; BirdLife International, 2019). Some studies 483 have suggested that $F_{I S}$ values tend to be lower (more outbred) when estimates are calculated 484 using only samples from juveniles, and higher (more inbred) in samples from adults (Basset, 485 486 487 Ballouxf \& Perrin, 2001; Parreira \& Chikhi, 2015). This is a potential consequence of a heterozygote excess increased by reproductive events, which are later counteracted by dispersal (Basset, Ballouxf \& Perrin, 2001). Thus, we cannot exclude a potential underestimation bias in our estimates of inbreeding coefficients, since they were obtained from nestlings. Overall, the values of genetic diversity estimates were similar to those reported for several declining vulture species (Gautschi et al., 2003; Arshad et al. 2009; Çakmak et al., 2019), higher than those observed in other declining species (Kleinhans \& Willows-Munro, 2019), and even higher than in vulture species showing larger population size and stable or increasing demographic trends ( $L e$ Gouar et al., 2008; Arshad et al., 2009). Therefore, these results should be interpreted with caution because different markers were used to estimate genetic diversity indices within and among species (see Väli et al., 2008). In addition, low genetic diversity is not always the result of a reduction in effective population size, as the former can be high in species with very small, isolated, and declining populations (Kekkonen, Wikström \& Brommer, 2012; Woolaver et al., 2013). A low genetic diversity may be due to demographic bottlenecks and population rebounds, as well as due to founder events with a reduced number of individuals, and absence of random mating (Thévenon et al., 2003; Kekkonen, Wikström \& Brommer, 2012). Current levels of neutral genetic diversity, relatedness, and inbreeding are similar to those reported for this species in the study area and other regions in continental Spain using the same suite of microsatellite loci (Agudo et al., 2011a). However, the values reported previously for the study area are not strictly comparable with those presented here because the former partially include full-grown individuals of unknown geographical origin (natal nest), age, and cohort. These individuals can include immigrants from other genetic clusters and geographical areas due to natal dispersal and nonbreeding nomadic movements (IBERIS, 2007; Sanz-Aguilar et al., 2017).

Our results show a relatively high proportion (about $20 \%$ ) of dyads comprising half- and full-sibs relationships among nestlings born in different territories in each study year. Indeed, a proportion of nestlings from distant territories in each year were genetic full-siblings. However, we found no evidence of a relationship between pairwise geographic inter-territory distances and pairwise genetic relatedness between nestlings from different territories in each cohort. This suggests a low contribution of extra-pair paternity to these intra- and inter-nest kinship relationships. Although extra-pair copulation has been reported at low frequency in the Egyptian vulture (Donázar, Ceballos \& Tella, 1994), the contribution to extra-pair paternity remains generally unexplored in vultures (Le Gouar et al., 2011). Our results showed exclusive full-sib 
517 relationships between nestlings from the same nest and cohort (broods of two siblings).

518 However, we found two half-sib relationships in the familiar lineage with known genealogy.

519 This can be indicative of slight and conservative deviations in the kinship assignation due to

520 allelic frequency, which deserves further assessment including more parents and offspring with

521 known pedigree. The assessment of genetic relatedness using genome-wide SNP loci could

522 improve the estimates (Flanagan \& Jones, 2019), although our microsatellite panel with a

523 probability of an accurate kinship assignment higher than 90\% seems reliable enough for the

524 aims of this study. Proportions of dyads falling in the kinship categories were higher than those

525 recorded in other vulture species, although these relatedness estimates were calculated for wild

526 and captive full-grown individuals (Gautschi et al., 2003; Ishtiaq et al., 2015). Given that these

527 studies analysed relatedness of individuals of different ages, they can include actual parent-

528 offspring relationships and full and half siblings from different cohorts. Instead, we found

529 closely related individuals among nestlings from the same cohorts but distant territories, which

530 clearly indicate that their parents were also closely related within and between pair mates from

531 different territories. At the scale of the whole population, we found that most territories showed

532 closely related individuals among the nestlings sampled in each study year. Indeed, nestlings of

533 each particular territory were closely related to those from a variable number of other territories

534 in each year. For instance, nestlings from three territories were closely related to those from

535 other seven territories each in 2006, when the sampling was more extensive, while nestlings from

536 one territory were closely related to those from up four territories in 2018. This implies that each

537 one of these nestlings was closely related to those from about half of the territories sampled each

538 year. Given that we sampled a representative proportion of the successful pairs each year, this

539 further indicates a high relatedness in the population. Overall, this highlights the importance of

540 knowing natal origin, age, and cohort in the assessment of genetic diversity and relatedness of

541 wildlife populations.

542

543

544

545

546

547

\section{Demographic history}

The analysis of bottlenecks detected a clear signature of genetic contractions during the last decades, coupled with the recent decline according to census and effective population size in the study area and other regions included in the same genetic cluster (Carrete et al., 2007; Agudo

548 et al., 2011a; Sanz-Aguilar et al., 2017). The significance observed in the heterozygosity excess

549 contrasts with the consistent and non-significant results of the M-ratio test in both study years,

550 which indicate that historical bottlenecks for the last centuries or millennia are not evident

551

552

553

554

555

556 (Williamson-Natesan, 2005; Peery et al., 2012). However, it is important to highlight that statistical power of bottlenecks tests is highly related to the number of samples and markers used, which in many cases affect the detection of historical population reductions (Peery et al., 2012; Hoban, Gaggiotti \& Bertorelle, 2013). Furthermore, the different sensitivity of heterozygosityexcess and M-ratio tests to possible violations of mutation model assumptions may affect the inferences about the timing of population declines (Peery et al., 2012). Therefore, we cannot 
557 completely rule out the occurrence of historical bottlenecks (distant past) in this population. The

558

559

560

561

562

563

564

565

566

567

568

569

570

571

572

573

574

575

576

577

578

579

580

581

582

583

584

585

586

587

588

589

590

591

592

593

594

595

596

clear signature of recent bottlenecks disagrees with the relatively high values of genetic diversity estimates. This apparent contradiction may arise because of long generation times owing to delayed breeding in this long-lived species (Sanz-Aguilar et al., 2017) can still reflect the retained genetic diversity in the parents of the nestlings analysed. This time lag associated to a slow pace of life could act as an intrinsic buffer to stave off genetic erosion in long-lived species (Hailer et al. 2006). This implies that long-term studies are necessary to adequately detect temporal changes in genetic diversity in these species. Given that Egyptian vultures can reproduce during many consecutive years across their long lifespans (Sanz-Aguilar et al., 2017), some of these breeders can be old enough to still harbour relatively high genetic diversity typical of not bottlenecked populations. In support of this possibility, no evidence of recent bottlenecks was found in the study area sampled prior to our study (TPM model, $P=0.153$, from Agudo et al., 2011a). This suggests that the impact of recent bottlenecks has increased in the last two decades to the point that it can be observed in its current progression in parallel to the reduction of the effective and census population size, but still without a clear reflection in genetic diversity estimates (see also Çakmak et al., 2019). However, the interpretation of these estimates should be made with caution when the proportion of closely related individuals in the population is high (Gautschi et al., 2003). In addition, the values of relatedness previously reported for the study area were obtained by pooling data from local nestlings with full-grown individuals of unknown natal origin, age, and cohort captured in foraging areas (IBERIS, 2007; Agudo et al., 2011a). Therefore, the lack of recent bottlenecks previously to our sampling could arise through an increase in genetic diversity by including individuals from other geographic regions and genetic clusters in the relatively continuous distribution range across central-north Iberia (Agudo et al., 2011a). This rationale could also apply to our data because, although the nestlings were sampled in a relatively small area of the distribution range of this genetic cluster, a small proportion of breeders could have been born outside the study area. In this case, the evidence of recent bottlenecks is supported by our conservative data, potentially including a proportion of offspring from immigrant individuals, which should be confirmed with a more extensive assessment over a larger geographical area.

\section{Implications of inbreeding and emerging pathogens in conservation}

The increase of close kin among mated breeders in small populations can lead to inbreeding depression. The consequences of a reduction of genetic diversity on offspring health and fitness can be severe for the affected populations (Charlesworth \& Willis, 2009). This is a critical factor in the conservation of endangered species when it occurs rapidly enough to preclude the purging of deleterious alleles (Brook et al., 2002; Fox, Scheibly \& Reed, 2008). Consequently, host susceptibility to disease agents is expected to increase due to inbreeding, although their effects on health can surface depending on whether the population is exposed to particularly dangerous and contagious pathogens (Smith, Sax \& Lafferty, 2006; Gupta, Robin \&

Peer) reviewing PDF | (2020:12:56011:1:1:NEW 9 Feb 2021) 
597 Dharmarajan, 2020). The evidence of recent bottlenecks and the reduction in census and 598 effective population size coincided in time with the first evidence in this species of close 599 inbreeding, confirmed by pedigree of individually-marked nestlings monitored subsequently, and 600 by genetic analysis. The inbred pair showed low reproductive success (only one apparently 601 healthy nestling raised from four reproductive attempts) and the first evidence in this species of 602 lethal feather malformations in offspring, which suggests a possible cause-and-effect 603 relationship. The affected nestling showed alterations in the overall plumage that precluded 604 fledging and these malformations remained the following two years in captivity. This kind of 605 feather dystrophy resembles those characterizing the pinching off syndrome reported associated to inbreeding in several raptor species in absence of any identified aetiological agent (Müller et 607 al., 2007). Similar malformations have been recorded in parrot and allies (Psittaciformes)

608 affected by the beak and feather disease virus (BFDV), and recently this avian circovirus has

609 been recorded affecting non-psittacine species, especially in small and isolated populations and

610 species with low genetic diversity (Raidal \& Peters 2018). We found that the nestling with generalized feather malformations was positive for this virus, which genetic sequence is

612 currently being characterized to determine its phylogenetic position informing on its potential

613 origin (Harkins et al., 2014; Morinha et al., 2020). In contrast, the apparently healthy sibling

614 (born in 2020) of the affected offspring (born in 2018) from the same inbred pair was negative to 615 BFDV. This suggests a potential interaction between inbreeding and malformation depending on 616 infection by BFDV, although other non-surveyed pathogens or pollutants could be involved in

617 disease causation, which requires further research. In support of an interaction between

618

619

620

621

622

623

624

625

626

627

628

629

630

631

632

\section{Acknowledgements}

634 We thank J.L. González del Barrio, Ó. Frías, B. Arroyo, F. Martínez and A. González for their 635 help with fieldwork, and J.A. Donázar for providing the microsatellite markers. Funds were 636 inbreeding and malformation due to BFDV, we found other BFDV-positive nestlings in the population ( $n=13)$, but no other with malformations has been recorded in previous studies (Blanco et al. 2017, 2020; Sanz et al.,2017).

\section{Conclusions}

Our study highlights on high relatedness, recent demographic bottlenecks, and inbreeding as concerning and increasing threats potentially reducing the adaptive potential of this declining population. This may arise directly through the effects of genetic erosion on health and fitness, and in combination with the detrimental effects of food-born pharmaceuticals and pathogens, including BFDV recorded for the first time in this species. Further research is needed to understand the relationships between demographic bottlenecks, inbreeding, susceptibility to pathogens, and health in the Egyptian vulture and other species of conservation concern. provided by the projects CGL2009-12753-C02-01/BOS, CGL2010-15726 and PID2019-

Peer) reviewing PDF | (2020:12:56011:1:1:NEW 9 Feb 2021) 
637 109685GB-I00 of Spanish Ministry of Science and Innovation. F.M. was supported by a Juan de 638 la Cierva postdoctoral fellowship from Spain's Ministry of Science and Innovation (FJCI-2017639 32055).

640

641

\section{References}

643 Agudo R, Roques S, Galarza JA, Rico C, Hiraldo F, Donázar JA. 2008. Isolation and characterization 644 of 18 microsatellite loci in the Egyptian vulture (Neophron percnopterus). Conservation Genetics 9:13456451348 DOI 10.1007/s10592-007-9486-9.

646 Agudo R, Rico C, Hiraldo F, Donázar JA. 2011a. Evidence of connectivity between continental and 647 differentiated insular populations in a highly mobile species. Diversity and Distributions 17:1-12 DOI 648 10.1111/j.1472-4642.2010.00724.x.

649 Agudo R, Alcaide M, Rico C, Lemus JA, Blanco G, Hiraldo F, Donazar JA. 2011b. Major 650 histocompatibility complex variation in insular populations of the Egyptian vulture: inferences about the 651 roles of genetic drift and selection. Molecular Ecology 20:2329-2340 DOI 10.1111/j.1365-

652 294X.2011.05107.x.

653 Agudo R, Carrete M, Alcaide M, Rico C, Hiraldo F, Donazar JA. 2012. Genetic diversity at neutral 654 and adaptive loci determines individual fitness in a long-lived territorial bird. Proceedings of the Royal 655 Society of London. Series B, Biological sciences 279:3241-3249 DOI 10.1098/rspb.2011.2606.

656 Allentoft ME, O'Brien J. 2010. Global amphibian declines, loss of genetic diversity and fitness: a 657 review. Diversity 2:47-71 DOI 10.3390/d2010047.

658 Amery-Gale J, Marenda MS, Owens J, Eden PA, Browning GF, Devlin JM. 2017. A high prevalence 659 of beak and feather disease virus in non-psittacine Australian birds. Journal of Medical Microbiology 660 66:1005-1013 DOI 10.1099/jmm.0.000516.

661 Anderson AD, Weir BS. 2007. A maximum-likelihood method for the estimation of pairwise relatedness 662 in structured populations. Genetics 176:421-440 DOI 10.1534/genetics.106.063149.

663 Aparicio JM, Ortego J, Cordero PJ. 2006. What should we weigh to estimate heterozygosity, alleles or 664 loci?. Molecular Ecology 15:4659-4665 DOI 10.1111/j.1365-294X.2006.03111.x.

665 Arshad M, Pedall I, González J, Wink M. 2009. Genetic variation of four gyps species (Gyps

666 bengalensis, G. africanus, G. indicus and G. fulvus) based on microsatellite analysis. Journal of Raptor

667 Research 43:227-236 DOI 10.3356/JRR-08-91.1.

668 Basset P, Ballouxf F, Perrin N. 2001. Testing demographic models of effective population size.

669 Proceedings of the Royal Society of London. Series B, Biological Sciences 268:311-317 DOI

670 10.1098/rspb.2000.1359.

671 Becker DJ, Streicker DG, Altizer S. 2015. Linking anthropogenic resources to wildlife-pathogen

672 dynamics: A review and meta-analysis. Ecology Letters 18:483-495 DOI 10.1111/ele.12428.

673 BirdLife International. 2019. Neophron percnopterus. The IUCN Red List of Threatened Species 2019:

674 e.T22695180A154895845. Downloaded on 30 January 2021. DOI 10.2305/IUCN.UK.2019-

675 3.RLTS.T22695180A154895845.en.

676 Blanco G. 2014. Can livestock carrion availability influence diet of wintering red kites? Implications of 677 sanitary policies in ecosystem services and conservation. Population Ecology 56:593-604 DOI

678 10.1007/s10144-014-0445-2.

679 Blanco G. 2018. Supplementary feeding as a source of multiresistant Salmonella in endangered Egyptian 680 vultures. Transboundary and Emerging Diseases 65:806-816 DOI 10.1111/tbed.12806. 
681 Blanco G, Junza A, Barrón D. 2017. Food safety in scavenger conservation: diet-associated exposure to

682

683

684

685

686

687

688

689

690

691

692

693

694

695

696

697

698

699

700

701

702

703

704

705

706

707

708

709

710

711

712

713

714

715

716

717

718

719

720

721

722

723

724 livestock pharmaceuticals and opportunist mycoses in threatened cinereous and Egyptian vultures. Ecotoxicology and Environmental Safety 135:292-301 DOI 10.1016/j.ecoenv.2016.10.009.

Blanco G, Díaz de Tuesta JA. 2018. Culture-and molecular-based detection of swine-adapted Salmonella shed by avian scavengers. Science of the Total Environment 634:1513-1518 DOI 10.1016/j.scitotenv.2018.04.089.

Blanco G, Díaz de Tuesta JA. 2020. Seasonal and spatial occurrence of zoonotic Salmonella serotypes in griffon vultures at farmland environments: Implications in pathogen pollution and ecosystem services and disservices. Science of the Total Environment. DOI 10.1016/j.scitotenv.2020.143681.

Blanco G, Cortés-Avizanda A, Frías Ó, Arrondo E, Donázar JA. 2019. Livestock farming practices modulate vulture diet-disease interactions. Global Ecology Conservation 17:e00518 DOI 10.1016/j.gecco.2018.e00518.

Blanco G, López-Hernández I, Morinha F, López-Cerero L. 2020. Intensive farming as a source of bacterial resistance to antimicrobial agents in sedentary and migratory vultures: Implications for local and transboundary spread. Science of the Total Environment 739:140356 DOI 10.1016/j.scitotenv.2020.140356.

Blanco G, Morinha F, Roques S, Hiraldo F, Rojas A, Tella JL. 2011. Fine-scale genetic structure in the critically endangered red-fronted macaw in the absence of geographic and ecological barriers. Scientific Reports 11:556 DOI 10.1038/s41598-020-79575-6.

Bouzat JL. 2010. Conservation genetics of population bottlenecks: the role of chance, selection, and history. Conservation Genetics 11:463-478 DOI 10.1007/s10592-010-0049-0.

Brook BW, Tonkyn DW, O'Grady JJ, Frankham R. 2002. Contribution of inbreeding to extinction risk in threatened species. Conservation Ecology 6:16.

Çakmak E, Akin Pekşen Ç, Kİrazli C, Yamaç E, Bensch S, Bİlgİn CC. 2019. Genetic diversity is retained in a bottlenecked Cinereous Vulture population in Turkey. Ibis 161:793-805 DOI 10.1111/ibi.12685.

Carrete M, Grande JM, Tella JL, Sánchez-Zapata JA, Donázar JA, Díaz-Delgado R, Romo A. 2007. Habitat, human pressure, and social behavior: Partialling out factors affecting large-scale territory extinction in an endangered vulture. Biological Conservation 136:143-154 DOI 10.1016/j.biocon.2006.11.025.

Charlesworth D, Willis JH. 2009. The genetics of inbreeding depression. Nature Reviews Genetics 10:783-796 DOI 10.1038/nrg2664.

Cornuet JM, Luikart G. 1996. Description and power analysis of two tests for detecting recent population bottlenecks from allele frequency data. Genetics 144:2001-2014.

Cramp S, Simmons KEL (eds.) 1980. Handbook of the birds of Europe, the Middle East and North Africa: the birds of the Western Palearctic, Vol. 2: Hawks to Bustards. New York: Oxford University Press.

Crnokrak P, Barrett SCH. 2002. Purging the genetic load: a review of the experimental evidence. Evolution 56:2347-2358 DOI 10.1111/j.0014-3820.2002.tb00160.x.

Cunningham AA, Daszak P, Wood JL. 2017. One Health, emerging infectious diseases and wildlife: two decades of progress? Philosophical Transactions of the Royal Society of London. Series B, Biological Sciences 372:20160167 DOI 10.1098/rstb.2016.0167.

Davidović S, Jelić M, Marinković S, Mihajlović M, Tanasić V, Hribšek I, Sušić G, Dragićević M, Stamenković-Radak M. 2020. Genetic diversity of the Griffon vulture population in Serbia and its 
725 importance for conservation efforts in the Balkans. Scientific Reports 10:20394 DOI 10.1038/s41598-

726 020-77342-1.

727 Del Hoyo J, Elliott A, Sargatal JE. 1994. Handbook of the birds of the world. Volume 2. New World

728 vultures to guinea fowl. Barcelona: Lynx Edicions.

729 del Moral JC. 2009. El alimoche común en España. Población reproductora en 2008 y método de censo.

730 (JC del Moral, Ed.). - SEO/Birdlife, Madrid, Spain.

731 Donázar JA. 1993. Los Buitres lbéricos: biología y conservación. J.M. Reyero, Madrid, Spain.

732 Donázar JA, Ceballos O, Tella JL. 1994. Copulation behaviour in the Egyptian vulture Neophron

733 percnopterus. Bird Study 41:37-41 DOI 10.1080/00063659409477195.

734 Donázar JA, Cortés-Avizanda A, Ceballos O, Arrondo E, Grande JM, Serrano D. 2020. Epizootics

735 and sanitary regulations drive long-term changes in fledgling body condition of a threatened vulture.

736 Ecological Indicators 113:106188 DOI 10.1016/j.ecolind.2020.106188.

737 Flanagan SP, Jones AG. 2019. The future of parentage analysis: From microsatellites to SNPs and

738 beyond. Molecular Ecology 28:544-567 DOI 10.1111/mec.14988.

739 Fox CW, Scheibly KL, Reed DH. 2008. Experimental evolution of the genetic load and its implications

740 for the genetics of inbreeding depression. Evolution 62:2236-2249 DOI 10.1111/j.1558-

741 5646.2008.00441.x.

742 Frankham R. 1996. Relationship of genetic variation to population size in wildlife. Conservation

743 Biology 10: 1500-1508 DOI 10.1046/j.1523-1739.1996.10061500.x.

744 Frankham R, Ballou JD, Briscoe DA. 2002. Introduction to conservation genetics. Cambridge

745 University Press, Cambridge

746 Frankham R. 2010. Challenges and opportunities of genetic approaches to biological conservation.

747 Biological Conservation 143:1919-1927 DOI 10.1016/j.biocon.2010.05.011.

748 Fridolfsson AK, Ellegren H. 1999. A simple and universal method for molecular sexing of non-ratite

749 birds. Journal of Avian Biology 30:116-121 DOI 10.2307/3677252.

750 Garza JC, Williamson EG. 2001. Detection of reduction in population size using data from

751 microsatellite loci. Molecular Ecology 10:305-318 DOI 10.1046/j.1365-294X.2001.01190.x.

752 Gautschi B, Jacob G, Negro JJ, Godoy JA, Müller JP, Schmid B. 2003. Analysis of relatedness and

753 determination of the source of founders in the captive bearded vulture, Gypaetus barbatus, population.

754 Conservation Genetics 4:479-490 DOI 10.1023/A:1024730128819.

755 Godoy JA, Negro JJ, Hiraldo F, Donázar JÁ. 2004. Phylogeography, genetic structure and diversity in

756 the endangered bearded vulture (Gypaetus barbatus, L.) as revealed by mitochondrial DNA. Molecular

757 Ecology 13:371-390 DOI 10.1046/j.1365-294X.2003.02075.x.

758 Goudet J. 1995. FSTAT (version 1.2): a computer program to calculate F-statistics. Journal of Heredity

759 86:485-486 DOI 10.1093/oxfordjournals.jhered.a111627.

760 Gupta P, Robin VV, Dharmarajan G. 2020. Towards a more healthy conservation paradigm:

761 integrating disease and molecular ecology to aid biological conservation. Journal of Genetics 99:1-26

762 DOI 10.1007/s12041-020-01225-7.

763 Hailer F, Helander B, Folkestad AO, Ganusevich SA, Garstad S, Hauff P, Koren C, Nygård T,

764 Volke V, Vilà C, Ellegren H. 2006. Bottlenecked but long-lived: high genetic diversity retained in white-

765 tailed eagles upon recovery from population decline. Biology Letters 2:316-319 DOI

$76610.1098 / \mathrm{rsbl} .2006 .0453$.

767 Harkins GW, Martin DP, Christoels A, Varsani A. 2014. Towards inferring the global movement of

768 beak and feather disease virus. Virology 450:24-33 DOI 10.1016/j.virol.2013.11.033. 
769 Hatchwell BJ. 2010. Cryptic kin selection: kin structure in vertebrate populations and opportunities for 770 kin-directed cooperation. Ethology 116:203-216 DOI 10.1111/j.1439-0310.2009.01732.x.

771 Hauser L, Baird M, Hilborn RAY, Seeb LW, Seeb JE. 2011. An empirical comparison of SNPs and

772 microsatellites for parentage and kinship assignment in a wild sockeye salmon (Oncorhynchus nerka)

773 population. Molecular Ecology Resources 11:150-161 DOI 10.1111/j.1755-0998.2010.02961.x.

774 Hoban SM, Gaggiotti OE, Bertorelle G. 2013. The number of markers and samples needed for

775 detecting bottlenecks under realistic scenarios, with and without recovery: a simulation-based study.

776 Molecular Ecology 22:3444-3450 DOI 10.1111/mec.12258.

777 Holderegger R, Wagner HH. 2008. Landscape genetics. Bioscience 58:199-207 DOI 10.1641/B580306.

778 IBERIS. 2007. Memoria final de la captura y radio seguimiento del Alimoche (Neophron percnopterus)

779 en las Hoces del Río Riaza (Segovia) 2006. Resumen de los trabajos realizados en el periodo 2000-2006.

780 Unpublished report. IBERIS- Estudios y Actividades Medioambientales, Rivas Vaciamadrid, Madrid,

781 Spain.

782 Ishtiaq F, Prakash V, Green RE, Johnson J. 2015. Management implications of genetic studies for ex

783

784

785 Jeppsson T, Forslund, P. 2012. Can life history predict the effect of demographic stochasticity on 786 extinction risk? American Naturalist 179:706-720 DOI 10.1086/665696.

787 Johne R, Müller H. 1998. Avian polyomavirus in wild birds: genome analysis of isolates from 788 Falconiformes and Psittaciformes. Archives of Virology 143:1501-1512 DOI 10.1007/s007050050393.

789 Kalinowski ST, Wagner AP, Taper ML. 2006. ML-RELATE: a computer program for maximum 790 likelihood estimation of relatedness and relationship. Molecular Ecology Notes 6:576-579 DOI 791 10.1111/j.1471-8286.2006.01256.x.

792 Kekkonen J, Wikström M, Brommer JE. 2002. Heterozygosity in an isolated population of a large 793 mammal founded by four individuals is predicted by an individual-based genetic model. Plos One 794 7:e43482 DOI 10.1371/journal.pone.0043482.

795 Keller LF, Grant PR, Grant BR, Petren K. 2002. Environmental conditions affect the magnitude of

796 inbreeding depression in survival of Darwin's finches. Evolution 56:1229-1239 DOI 10.1111/j.0014-

797 3820.2002.tb01434.x.

798 Keller LF, Waller DM. 2002. Inbreeding effects in wild populations. Trends in Ecology and Evolution 799 17:230-241 DOI 10.1016/S0169-5347(02)02489-8.

800 Kleinhans C, Willows-Munro S. 2019. Low genetic diversity and shallow population structure in the 801 endangered vulture, Gyps coprotheres. Scientific Reports 9:5536 DOI 10.1038/s41598-019-41755-4.

802 Kopelman NM, Mayzel J, Jakobsson M, Rosenberg NA, Mayrose I. 2015. Clumpak: a program for

803 identifying clustering modes and packaging population structure inferences across K. Molecular Ecology

804 Resources 15:1179-1191 DOI 10.1111/1755-0998.12387.

805 Kretzmann MB, Capote N, Gautschi B, Godoy JA, Donázar JA, Negro JJ. 2003. Genetically distinct

806 island populations of the Egyptian vulture (Neophron percnopterus). Conservation Genetics 4:697-706

807 DOI 10.1023/B:COGE.0000006123.67128.86.

808 Lande R, Enger S, Sæther BE. 2003. Stochatic population dynamics in ecology and conservation.

809 Oxford University Press, Oxford, UK.

810 Le Gouar P, Rigal F, Boisselier-Dubayle MC, Sarrazin F, Arthur C, Choisy JP, Hatzofe O,

811 Henriquet S, Lécuyer P, Tessier C, Susic G. 2008. Genetic variation in a network of natural and 
812 reintroduced populations of Griffon vulture (Gyps fulvus) in Europe. Conservation Genetics 9:349-359

813 DOI 10.1007/s10592-007-9347-6.

814 Le Gouar P, Sulawa J, Henriquet S, Tessier C, Sarrazin F. 2011. Low evidence for extra-pair

815 fertilizations in two reintroduced populations of Griffon Vulture (Gyps fulvus). Journal of Ornithology

816 152:359-364 DOI 10.1007/s10336-010-0593-x.

817 Leberg PL, Firmin BD. 2008. Role of inbreeding depression and purging in captive breeding and

818 restoration programmes. Molecular Ecology 17:334-343 DOI 10.1111/j.1365-294X.2007.03433.x.

819 Li CC, Weeks DE, Chakravarti A. 1993. Similarity of DNA fingerprints due to chance and relatedness.

820 Human Heredity 43:45-52 DOI 10.1159/000154113.

821 Lowe WH, Allendorf FW. 2010. What can genetics tell us about population connectivity?. Molecular

822 Ecology 19:3038-3051 DOI 10.1111/j.1365-294X.2010.04688.x.

823 Luikart G, Allendorf FW, Cornuet JM, Sherwin WB. 1998. Distortion of allele frequency

824 distributions provides a test for recent population bottlenecks. Journal of Heredity 89:238-247 DOI

825 10.1093/jhered/89.3.238.

826 Lynch M. 1988. Estimation of relatedness by DNA fingerprinting. Molecular Biology and Evolution

827 5:584-599 DOI 10.1093/oxfordjournals.molbev.a040518.

828 Lynch M, Ritland K. 1999. Estimation of pairwise relatedness with molecular markers. Genetics

829 152:1753-1766 DOI 10.1093/genetics/152.4.1753.

830 Martin LB, Hopkins WA, Mydlarz LD, Rohr JR. 2010. The effects of anthropogenic global changes

831 on immune functions and disease resistance. Annals of the New York Academy of Sciences 1195:129-148

832 DOI 10.1111/j.1749-6632.2010.05454.x.

833 Martinez F, Blanco G. 2002. Use of alternative nests for clutch replacement in the Egyptian vulture

834 Neophron percnopterus. Ardeola 49:297-299.

835 Martínez-Cruz B, Camarena MM. 2018. Conservation Genetics in Raptors. In Birds of Prey (pp. 339-

836 371). Springer, Cham.

837 Morinha F, Carrete M, Tella JL, Blanco G. 2020. High prevalence of novel beak and feather disease

838 virus in sympatric invasive parakeets introduced to Spain from Asia and South America. Diversity 12:192

839 DOI 10.3390/d12050192.

840 Müller K, Altenkamp R, Brunnberg L, Fašungová L, Freymann H, Frölich K, Kollmann R, Krone

841 O, Literák I, Mizera T, Sömmer P. 2007. Pinching off syndrome in free-ranging white-tailed sea eagles

842 (Haliaeetus albicilla) in Europe: frequency and geographic distribution of a generalized feather

843 abnormality. Journal of Avian Medicine and Surgery 21:103-109 DOI 10.1647/1082-

844 6742(2007)21[103:POSIFW]2.0.CO;2.

845 O'Grady JJ, Reed DH, Brook BW, Frankham R. 2004. What are the best correlates of extinction risk?

846 Biological Conservation 118:513-520 DOI 10.1016/j.biocon.2003.10.002.

847 O'Grady JJ, Brook BW, Reed DH, Ballou JD, Tonkyn DW, Frankham R. 2006. Realistic levels of

848 inbreeding depression strongly affect extinction risk in wild populations. Biological Conservation

849 133:42-51 DOI 10.1016/j.biocon.2006.05.016.

850 Palstra FP, Ruzzante DE. 2008. Genetic estimates of contemporary effective population size: what can

851 they tell us about the importance of genetic stochasticity for wild population persistence?. Molecular

852 Ecology 17:3428-3447 DOI 10.1111/j.1365-294X.2008.03842.x.

853 Parreira BR, Chikhi L. 2015. On some genetic consequences of social structure, mating systems,

854 dispersal, and sampling. Proceedings of the National Academy of Sciences of the United States of

855 America 112:E3318-E3326 DOI 10.1073/pnas.1414463112. 
856

857

858

859

860

861

862

863

864

865

866

867

868

869

870

871

872

873

874

875

876

877

878

879

880

881

882

883

884

885

886

887

888

889

890

891

892

893

894

895

896

897

898

899

Peakall R, Smouse PE. 2012. GenAlEx 6.5: genetic analysis in Excel. Population genetic software for teaching and researchdan update. Bioinformatics 28:2537-2539 DOI 10.1111/j.1471-8286.2005.01155.x. Peery MZ, Kirby R., Reid B. N., Stoelting R., Douchet-Beer E., Robinson S., Vasquez-Carrillo C, Pauli JN, Palsbøll PJ. 2012. Reliability of genetic bottleneck tests for detecting recent population declines. Molecular Ecology 21:3403-3418 DOI 10.1111/j.1365-294X.2012.05635.x.

Piry S, Luikart G, Cornuet JM. 1999. BOTTLENECK: a computer program for detecting recent reductions in the effective population size using allele frequency data. Journal of Heredity 90:502-503 DOI 10.1093/jhered/90.4.502.

Pitarch A, Gil C, Blanco G. 2017. Oral mycoses in avian scavengers exposed to antimicrobials from livestock farming. Science of the Total Environment 605:139-146 DOI 10.1016/j.scitotenv.2017.06.144. Pitarch A, Gil C, Blanco G. 2020. Vultures from different trophic guilds show distinct oral pathogenic yeast signatures and co-occurrence networks. Science of the Total Environment 723:138166 DOI 10.1016/j.scitotenv.2020.138166.

Plaza PI, Blanco G, Lambertucci SA. 2020. Implications of bacterial, viral and mycotic microorganisms in vultures for wildlife conservation, ecosystem services and public health. Ibis 162:1109-1124 DOI https://doi.org/10.1111/ibi.12865.

Poulakakis N, Antoniou A, Mantziou G, Parmakelis A, Skartsi T, Vasilakis D, Elorriaga J, De la Puente J, Gavashelishvili A, Ghasabyan M, Katzner T, McGrady M, Batbayar N, Fuller M, Natsagdorj T. 2008. Population structure, diversity, and phylogeography in the near-threatened Eurasian black vultures Aegypius monachus (Falconiformes; Accipitridae) in Europe: insights from microsatellite and mitochondrial DNA variation. Biological Journal of the Linnean Society 95:859-872. 10.1111/j.10958312.2008.01099.x.

Pritchard JK, Stephens M, Donnelly P. 2000. Inference of population structure using multilocus genotype data. Genetics 155:945-959.

Pusey A, Wolf M. 1996. Inbreeding avoidance in animals. Trends in Ecology and Evolution 11:201-206 DOI 10.1016/0169-5347(96)10028-8.

Queller DC, Goodnight KF. 1989. Estimating relatedness using genetic markers. Evolution 43:258-275 DOI 10.1111/j.1558-5646.1989.tb04226.x.

Raidal SR, Peters A. 2018. Psittacine beak and feather disease: ecology and implications for conservation. Emu 118:80-93 DOI10.1080/01584197.2017.1387029.

Reed DH, Briscoe DA, Frankham R. 2002. Inbreeding and extinction: the effect of environmental stress and lineage. Conservation Genetics 3:301-307 DOI 10.1023/A:1019948130263.

Ritland K. 1996. Estimators for pairwise relatedness and individual inbreeding coefficients. Genetics Research 67:175-185. DOI 10.1017/S0016672300033620.

Roff DA. 2002. Life history evolution. Sinauer Associattes, Sunderland, MA.

Rousset F. 2008. genepop'007: a complete re-implementation of the genepop software for Windows and Linux. Molecular Ecology Resources 8:103-106 DOI 10.1111/j.1471-8286.2007.01931.x.

Sather BE, Coulson T, Grotan V, Engen S, Altwegg R, Armitage KB, Barbraud C, Becker PH, Blumstein DT, Dobson FS, Festa-Bianchet M, Gaillard JM, Jenkins A, Jones C, Nicoll MAC, Norris K, Oli MK, Ozgul A, Weimerskirch H. 2013. How Life History Influences Population Dynamics in Fluctuating Environments. American Naturalist 182:743-909 DOI 10.1086/673497.

Sanz-Aguilar A, Cortés-Avizanda A, Serrano D, Blanco G, Ceballos O, Grande JM, Tella JL, Donázar JA. 2017. Sex-and age-dependent patterns of survival and breeding success in a long-lived endangered avian scavenger. Scientific Reports 7:40204 DOI 10.1038/srep40204.

Peer] reviewing PDF | (2020:12:56011:1:1:NEW 9 Feb 2021) 
900 Smouse PE, Peakall R. 1999. Spatial autocorrelation analysis of individual multiallele and multilocus 901 genetic structure. Heredity 82:561-573 DOI 10.1038/sj.hdy.6885180.

902 Smith KF, Sax DF, Lafferty KD. 2006. Evidence for the role of infectious disease in species extinction

903 and endangerment. Conservation Biology 20:1349-1357 DOI 10.1111/j.1523-1739.2006.00524.x.

904 Smouse RPP, Peakall R. 2012. GenAlEx 6.5: genetic analysis in Excel. Population genetic software for 905 teaching and research — an update. Bioinformatics 28:2537-2539 DOI 10.1111/j.1471-8286.2005.01155.x.

906 Spencer CC, Neigel JE, Leberg PL. 2000. Experimental evaluation of the usefulness of microsatellite

907 DNA for detecting demographic bottlenecks. Molecular Ecology 9:1517-1528 DOI 10.1046/j.1365-

908 294x.2000.01031.x.

909 Spielman D, Brook BW, Briscoe DA, Frankham R. 2004. Does inbreeding and loss of genetic diversity 910 decrease disease resistance? Conservation Genetics 5:439-448 DOI

911 10.1023/B:COGE.0000041030.76598.cd.

912 Thévenon S, Bonnet A, Claro F, Maillard JC. 2003. Genetic diversity analysis of captive populations:

913 The Vietnamese sika deer (Cervus nippon pseudaxis) in zoological parks. Zoo Biology 22:465-475 DOI

914 10.1002/zoo.10091.

915 Thrasher DJ, Butcher BG, Campagna L, Webster MS, Lovette IJ. 2018. Double-digest RAD

916 sequencing outperforms microsatellite loci at assigning paternity and estimating relatedness: A proof of

917 concept in a highly promiscuous bird. Molecular Ecology Resources 18:953-965 DOI 10.1111/1755-

9180998.12771.

919 Väli Ü, Einarsson A, Waits L, Ellegren H. 2008. To what extent do microsatellite markers reflect 920 genome-wide genetic diversity in natural populations?. Molecular Ecology 17:3808-3817 DOI

921 10.1111/j.1365-294X.2008.03876.x.

922 Van Oosterhout C, Hutchinson WF, Wills DP, Shipley P. 2004. MICRO-CHECKER: software for 923 identifying and correcting genotyping errors in microsatellite data. Molecular Ecology Notes 4:535-538 924 DOI 10.1111/j.1471-8286.2004.00684.x.

925 van Overveld T, Blanco G, Moleón M, Margalida A, Sanchez-Zapata JA, de la Riva M, Donázar

926 JA. 2020. Integrating vulture social behavior into conservation practice. Condor. DOI

927 10.1093/condor/duaa035.

928 Waples R, Do C. 2008. LDNe: a program for estimating effective population size from data on linkage 929 disequilibrium. Molecular Ecology Resources 8:753-756 DOI 10.1111/j.1755-0998.2007.02061.x.

930 Wang J. 2002. An estimator for pairwise relatedness using molecular markers. Genetics 160:1203-1215 931 DOI 10.1093/genetics/160.3.1203.

932 Wang J. 2011. COANCESTRY: a program for simulating, estimating and analysing relatedness and 933 inbreeding coefficients. Molecular Ecology Resources 11:141-145 DOI 10.1111/j.1755-

934 0998.2010.02885.x.

935 Wang J. 2014. Marker-based estimates of relatedness and inbreeding coefficients: an assessment of 936 current methods. Journal of Evolutionary Biology 27:518-530 DOI 10.1111/jeb.12315.

937 Weinman LR, Solomon JW, Rubenstein DR. 2015. A comparison of single nucleotide polymorphism 938 and microsatellite markers for analysis of parentage and kinship in a cooperatively breeding bird.

939 Molecular Ecology Resources 15:502-511 DOI 10.1111/1755-0998.12330.

940 Weir BS, Cockerham CC. 1984. Estimating F-statistics for the analysis of population structure.

941 Evolution 38:1358-1370 DOI 10.2307/2408641. 
942 Willi Y, Van Buskirk J, Hoffmann AA. 2006. Limits to the adaptive potential of small populations.

943 Annual Review of Ecology, Evolution, and Systematics 37:433-458 DOI

944 10.1146/annurev.ecolsys.37.091305.110145.

945 Williamson-Natesan EG. 2005. Comparison of methods for detecting bottlenecks from microsatellite 946 loci. Conservation Genetics 6:551-562 DOI 10.1007/s10592-005-9009-5.

947 Willoughby JR, Sundaram M, Wijayawardena BK, Kimble SJ, Ji Y, Fernandez NB, Antonides JD, 948 Lamb MC, Marra NJ, DeWoody JA. 2015. The reduction of genetic diversity in threatened vertebrates 949 and new recommendations regarding IUCN conservation rankings. Biological Conservation 191: 495-

950 503. DOI 10.1016/j.biocon.2015.07.025.

951 Woolaver LG, Nichols RK, Morton ES, Stutchbury BJ. 2013. Population genetics and relatedness in a 952 critically endangered island raptor, Ridgway's Hawk Buteo ridgwayi. Conservation Genetics 14:559-571 953 DOI 10.1007/s10592-013-0444-4.

954 Wootton JT, Pfister CA. 2013. Experimental separation of genetic and demographic factors on 955 extinction risk in wild populations. Ecology 94:2117-2123 DOI 10.1890/12-1828.1. 


\section{Table $\mathbf{1}$ (on next page)}

Mean \pm SD values of genetic diversity, relatedness, and inbreeding of nestling Egyptian vultures sampled in 2006 and 2018, and both years pooled in Segovia, central Spain.

Genetic diversity was assessed by allelic richness $\left(A_{R}\right)$, observed heterozygosity $\left(H_{0}\right)$, and expected heterozygosity $\left(H_{\mathrm{E}}\right)$. Relatedness and inbreeding were assessed through Queller and Goodnight's pairwise relatedness values (QG-r), maximum likelihood estimates of relatedness (ML-r), inbreeding coefficients $\left(F_{15}\right)$, and homozygosity by loci $(H L) . n$ represents sample size $\left(A_{R}, H_{0}, H_{\mathrm{E}}\right.$ and $F_{\mathrm{IS}}$ - number of markers considered in the estimations; QG-r and ML-r number of pairwise comparisons; HL - number of individuals). Statistical differences between years were assessed by Mann-Whitney U-test. 
1

2

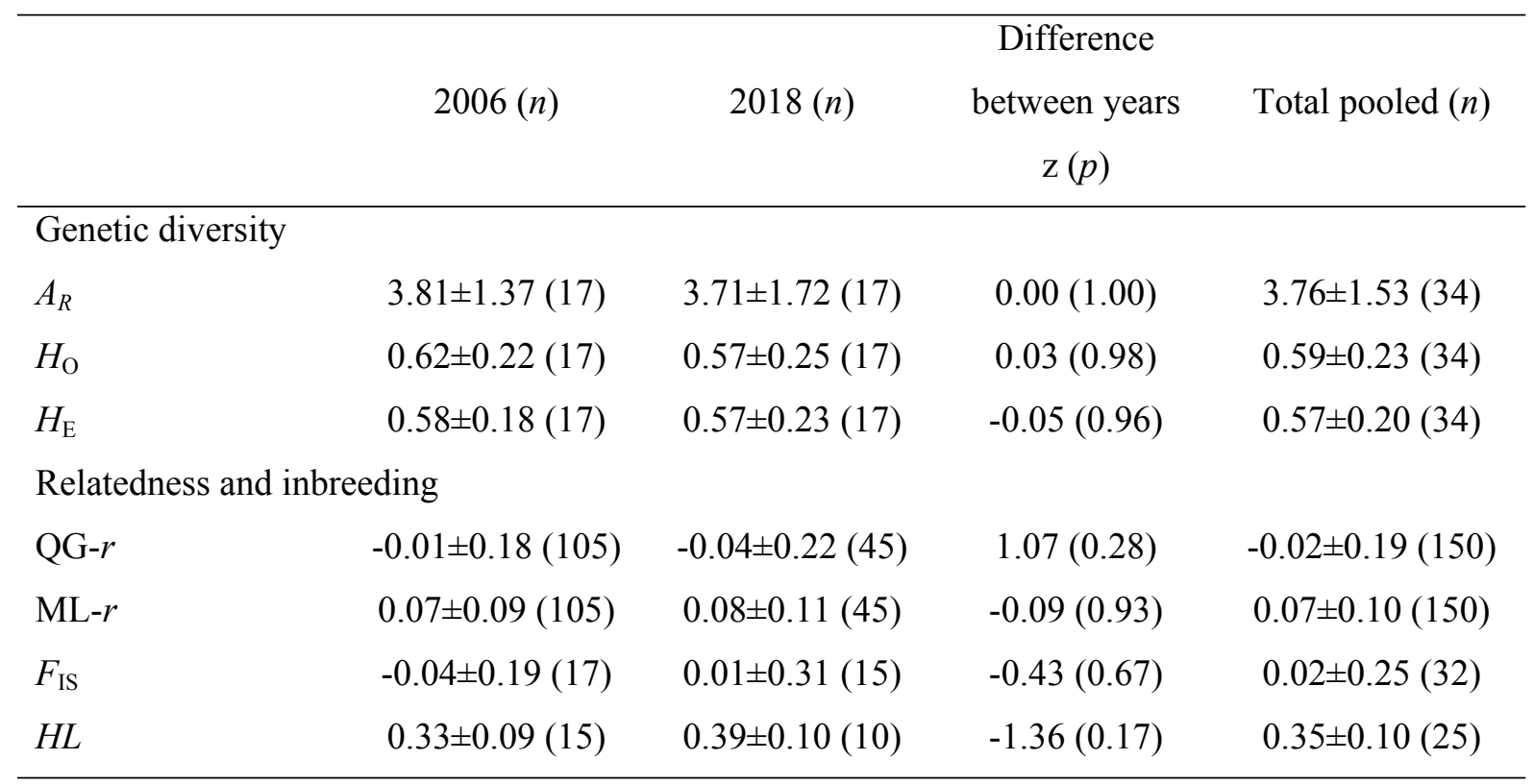

3 


\section{Table 2 (on next page)}

Results of the bottleneck analysis.

$P$-values of the one-tail Wilcoxon sign-rank tests for heterozygote excess are shown for the Two-Phase Model (TPM), Stepwise Mutation Model (SMM), and Infinite Allele Model (IAM). For the Mode-shift test, modes obtained for each group are indicated. 


\begin{tabular}{cccccc}
\hline \multirow{2}{*}{ Year } & $n$ & $\begin{array}{c}\text { TPM } \\
P-\end{array}$ & $\begin{array}{c}\text { SMM } \\
P-\end{array}$ & $\begin{array}{c}\text { IAM } \\
P-\end{array}$ & Mode-shift \\
& values & values & values & \\
\hline 2006 & 15 & $\mathbf{0 . 0 4 0}$ & 0.290 & $\mathbf{0 . 0 0 8}$ & Normal L-shaped \\
2018 & 10 & $\mathbf{0 . 0 0 3}$ & $\mathbf{0 . 0 1 7}$ & $<\mathbf{0 . 0 0 1}$ & Shifted mode \\
$2006+2018^{*}$ & 21 & $\mathbf{0 . 0 0 8}$ & 0.270 & $<\mathbf{0 . 0 0 1}$ & Normal L-shaped \\
\hline
\end{tabular}

*Only individuals from different territories 


\section{Figure 1}

Inferred relationships and geographic distribution of the offspring in 2018.

(A) Dyads of closely related Egyptian vulture nestlings from different territories sampled in Segovia, central Spain; the same colours of symbols represented together (circles represent females and squares represent males) were used for broods of two nestlings. (B) Geographic location of the sampled territories; the colours representing each territory are the same than those representing nestlings from these territories. The arrow indicates the dispersal from the natal to the breeding territory of an inbred pair formed of full-sibling from the same territory but different cohorts (see Fig. 3 for the genealogy of this familiar lineage).
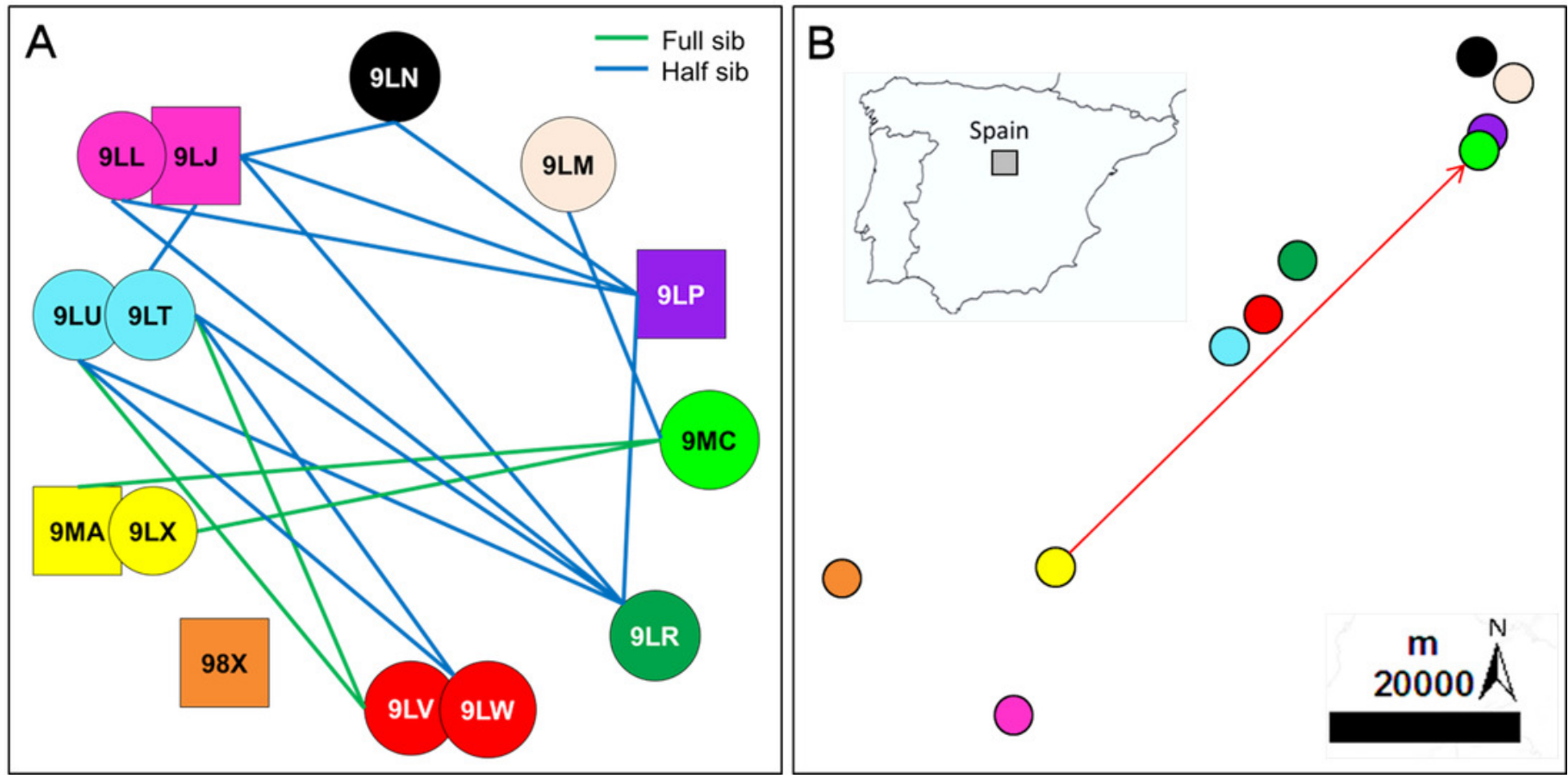


\section{Figure 2}

Frequency (\%) of territories with closely related (half- and full-sibs) nestling Egyptian vultures.

The data are represented attending to the number of territories with closely related nestlings in each study year. The specific and geographic representations of these relationships are shown in Fig. 1A, B, respectively, for nestlings from 2018. The number of territories (n) sampled each year is shown.

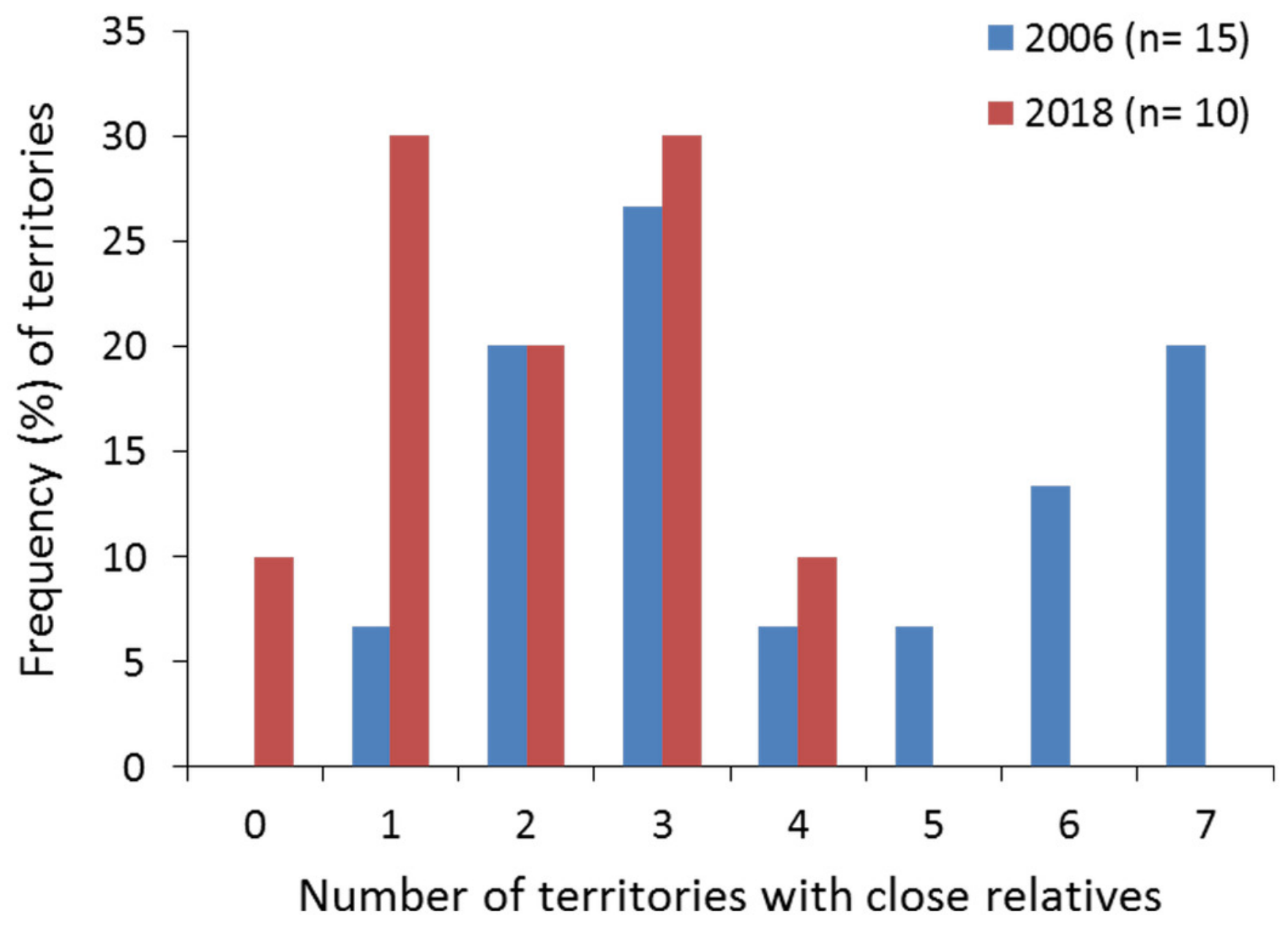




\section{Figure 3}

Pedigree of the Egyptian vulture familiar group analysed.

Circles represent females and squares males, including an inbred pair formed by full-siblings from different cohorts (ref. 291-32U) and their offspring. Double arrows represent mated pairs. Years are shown within orange rectangles. Dashed lines represent dyads with relatedness estimates corresponding to parent-offspring values, but actually corresponding to grandparents and grandchildren, the last being the offspring of the inbreed pair. All relationship categories between dyads of nestlings correspond to actual sibship, as determined by pedigree and confirmed from genotypic data. The estimate as unrelated of the unmarked progenitors of all nestlings except those from the inbreed pair was determined from genotypic data. The occurrence or absence of PBFV and malformations are shown for the offspring of the inbred pair. 


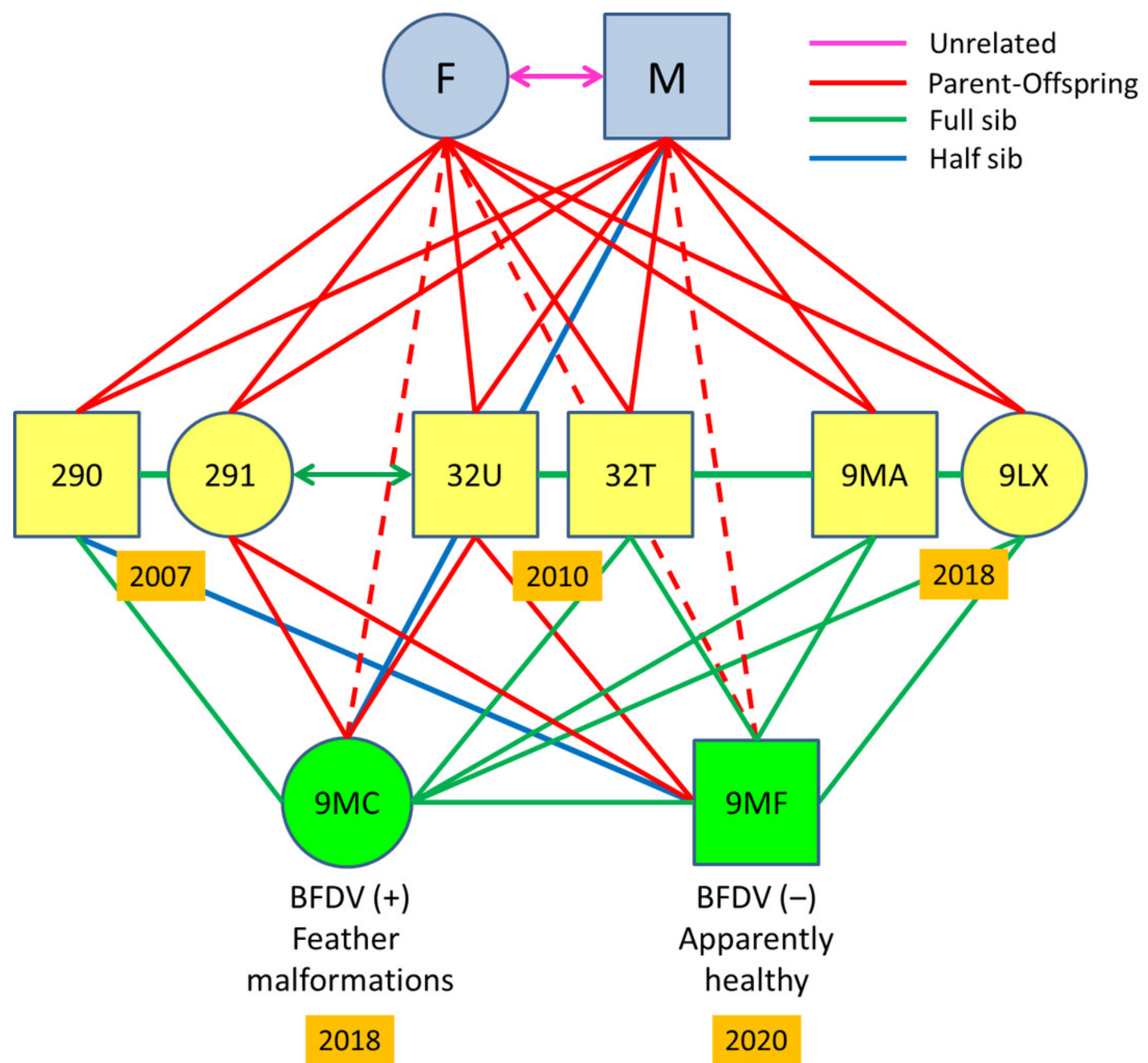


Figure 4

Fledgling Egyptian vulture with feather malformations, daughter of an inbred pair formed by full siblings.

(A) Alterations in feather structure and appearance across all the plumage. (B) Detail of the constricted calamus in all flight feathers with barbs appearing only in the distal part. Pictures: G. Blanco. 


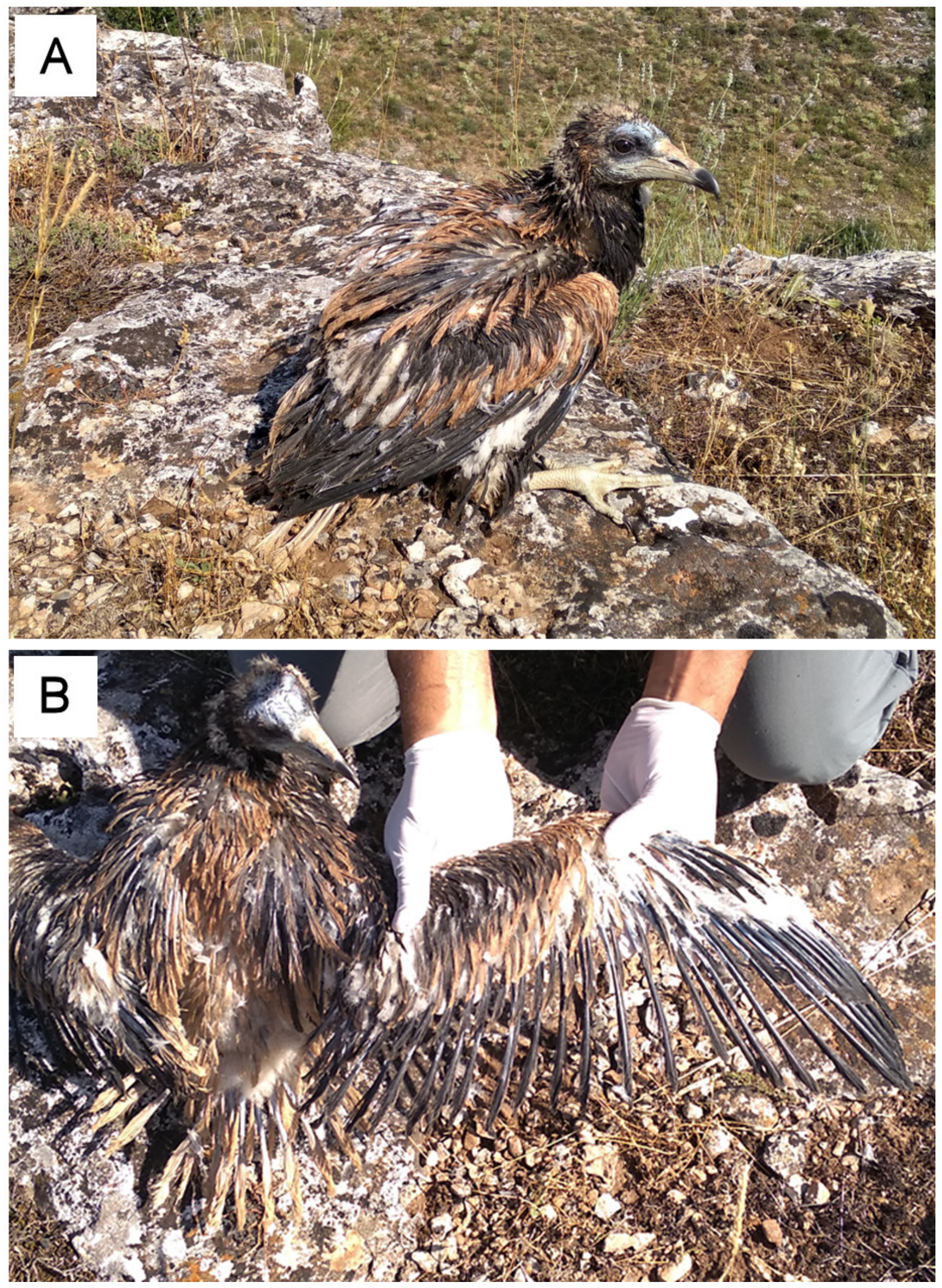

